\title{
Advances in Somatic Embryogenesis Research of Horticultural Plants
}

\author{
Aiqing $\mathrm{Ji}^{16^{* *}}$, Xueqing Geng ${ }^{2 *}$, Yan Zhang ${ }^{3}$, Hongyan $\mathrm{Yang}^{4}$, Guoliang $\mathrm{Wu}^{5,6 \#}$ \\ ${ }^{1}$ Department of Biology Science and Technology, Jinzhong College, Jinzhong, China; ${ }^{2}$ Department of Plant Cellular and Molecular \\ Biology, Ohio State University, Columbus, USA; ${ }^{3}$ Department of Horticultural Science, Xinyang Agricultural Junior College, Xin- \\ yang, China; ${ }^{4}$ Jinzhong City Meteorology Bureau of Shanxi Province, Jinzhong, China; ${ }^{5}$ College of Horticultural Science, Henan \\ Agricultural University, Zhengzhou, China; ${ }^{6}$ Henan Key Laboratory of Fruit and Cucurbit Biology, Zhengzhou, China. \\ Email: "walnut-wu@126.com
}

Received August $8^{\text {th }}, 2011$; revised September $16^{\text {th }}, 2011$; accepted November $10^{\text {th }}, 2011$.

\begin{abstract}
Advances in horticulture plant biotechnologies provide new opportunities for researchers to study the field of vegetative propagation and genetic engineering. Developments of clonal propagation methods, especially somatic embryogenesis (SE), have numerous potential applications. This paper reviewed progress of research on SE in horticultural plants in last decade; analyzed plant regeneration having both direct and indirect SE from the characteristics of occurrence means, but mainly in an indirect way; and discussed the impact factors of SE, as well as reviewed the research in the practical applications of horticulture plants SE in the practice.
\end{abstract}

Keywords: Horticultural Plants, Somatic Embryogenesis, Embryoid

\section{Introduction}

Plant somatic embryogenesis (SE) research has been investigated in plant tissue culture in recent years. The definition of SE is that the plant somatic cell develops into a new plant with the similar progress of zygotic embryo development [1]. The origination of embryogenesis is different between SE and zygotic embryogenesis; however, both embryogenesis are close in structure and bio-chemical properties [2]. Plant SE is the expression of plant cell totipotency, and the successful SE of different plants requires specific cultural environments [3]. The SE research progress of fruit trees is relatively slow compared with the rapid development of vegetables and flowers. Whereas, due to the nutrient and economic value of fruit trees in agricultural production, SE of fruit trees has made rapid progress in the past decade years. The author reviews the factors that affect SE and its application to the field of horticulture science in recent years, providing the reference for future embryogenesis research.

\section{The SE Pathway of Horticultural Plants}

\subsection{The Direct SE Pathway}

The definition of direct SE is that explants could directly induce somatic embryos. For example, the immature em-

*These authors contributed equally to this work. bryos and cotyledons of peach (Prunus persica L.) [4], the young embryos of cherry (Prunus avium L.) [5], the leaves of apple (Malus pumila Mill.) [6], the embryos of sugar beet (Beta vulgaris L.) [7], the young leaves of Bartlett (Pyrus communis L.) [8], the flowers of chrysanthemum (Dendranthema morifolium) [9], the leaves of carnation (Dianthus caryophyllus L.) [10] (Yantcheva A. et al., 1998), the scale leaves of lily (Lilium brownii var. viridulum) [11], the tender leaf of Kalanchoe blossfeldiana [12], and the leaves of Alaenopsis orchid [13] could all induce the somatic embryos to form regeneration plants.

\subsection{The Indirect SE Pathway}

The definition of indirect SE is that explants dedifferentiate to form callus, from which cells differentiate to form the somatic embryos. For example, the embryos of mango (Mangifera indica) [14], the male inflorescences of banana (Musa paradisiaca) [15], the leaves of grape ( $\mathrm{Vi}$ tis vinifera) [16], the bulb stems of garlic (Allium sativum L.) [17], the cotyledons of cucumber (Cucumis sativus) [18], and the young stems of Poinsettia (Euphorbia pulcherrima Willd) [19] and gypsophila (Gypsophila paniculata L.) [20] all could form somatic embryos and develop to regenerate plants by indirect SE.

In addition, some plants could induce somatic embryos 
by both direct and indirect SE. Examples include Chrysanthemum morifolium [21,22], cucumber [23], orchid [13], and walnut [24].

\section{The Impact Factors for SE of Horticultural Plants}

\subsection{Genotypes and Explants}

The genotype is the key factor in affecting plant SE. The frequency of SE has been shown to be quite diverse because of genotypic variation, even within the same genus. Not all of the species of an induced genus can be induced for SE. Because of the difference of genotypes, the extent and frequency of SE of the same variety are distinct. Yang et al.'s [25] research indicated that Yesanhan cucumber is an ideal genotype for SE of cucumber. When immature cotyledons from three sour cherry cultivars were tested, the ability to induce SE under identical cultural conditions and age of materials ranged from $41.43 \%$ to only $14.88 \%$ [24]. Different Early varieties of walnuts (Xiangling and Yuanfeng) have distinct frequencies of inducing somatic embryos when using the same explants [26]. There are only 5 species and 3 hybrids of walnut that have been reported to induce SE successfully depending on genotypes and explants [24]. Wang et al.'s study indicated the frequencies of callus and SE of 8 vegetable soybeans (Phaseolus vulgaris Linn.) with immature cotyledons were associated with their genotypes [27]. Bian et al. [28] have shown that the distinct genotypes of cyclamen (Cyclamen persicum Mill) play a very important role in inducing SE. The different frequency of SE, which is widely considered to pertain to their optimal inducible conditions, leads to various results. However, the specific inducible conditions could not easily be grasped by the researchers.

The status of physiology and development of explants impacts the SE. In general, the tissue with the highest level of metabolism and lowest level of differentiation would promote the induction of SE [29]. The inner filament base of Spathiphyllum floribundum is relatively easy to induce SE [30]. It has been shown that callus induction varied in different Euphorbia pulcherrima tissues, with the order of young stem $>$ young inflorescences $>$ young leaf [31]. The cotyledons of Citrtullus lanatus cv. Zhengkang No.4 placed facing down on the medium have higher somatic callus induction rates than when facing upwards [32]. It has been shown that the shoot apexes of Clematis Multi-Blue (Clematis florida Thunb) have the best ability to induce SE among young leaves, stem tips, and young stems [33]. Xin et al.'s [34] research indicated that the leaves of Anthuriuln andraeanum are much easier to induce SE than other explants. The callus formed on the apical end of walnut petioles exposed to the air is the real embryonic callus [35]. The research already indicated that the SE of the immature embryo of walnuts is better than that of mature embryo, and 6 to 11-week-old cotyledons of walnut (J. regia) after pollination had a relatively high ability to induce SE [24], while Eastern black walnut (J. nigra) needed 12 - 14 weeks after pollination. During the induction of SE from inflorescence explants of Freesia refracta, all somatic embryos appeared exclusively at the original morphological lower end, while no embryo was formed at the morphological upper end; these results were irrespective of gravity and the position of the explants on the medium [36]. Xin et al.'s [34] results indicated that the leaf sections of Anthuriuln andraeanum were suitable explants and expressed higher embryogenic potential than other explants. Therefore, selecting the distinct explants is the key factor of inducing SE.

\subsection{The Base Medium}

The components of the base medium play a complex role in SE. There are mainly 5 different media for the SE of horticultural plants: MS, SH, B5, DKW and WPM. MS is the basal media for the culture. Dewald and Wang [37] indicated that the effect of improved B5 was better than MS or WPM for the study of SE of mango. When applied on improved B5 media, it would induce normal cotyledons, and most of the somatic embryos developed normally at the early stage of heart-shape embryo. DKW is the best media for inducing the SE of walnut, but the effect of WPM is much better than DKW for the SE of black walnut. Under the same conditions, the frequency of SE of young embryos of walnuts in MS media is higher than in DKW; nonetheless, the frequency of the SE of cotyledons of walnuts in DKW media is higher than in MS. WPM has no effect on SE of both young embryos and cotyledons [24]. In summary, the SE of horticultural plants has different requirement for the media depending on the variation of genotypes, explants, and species of plants.

\subsection{Plant Growth Regulators (PGR)}

The effect of PGR is an important factor impacting SE and plant regeneration. In most cases, successful plant SE needs a mixture of the different concentration ratios of auxin and cytokinin (CTK), both of which are neces- sary for plant culture in vitro.

In general, 2,4-dickorophenoxyacetic (2, 4-D), which is one of the most important hormones inducing SE, has been widely used in horticultural plants. For instance, Papaya (Chaenomeles sinensis Koehne) [38], Grape (Vitis vinifera) [16], Peach (Prunus persica L.) [4], American chestnut (Castanea dentata) [39], Mango (Mangifera indica) [14], Rocket (Eruca Sativa Mill) [40], Lily [11]. 
The other type of auxin instead of 2.4-D would inhibit the SE. Nevertheless, the effect of 2.4-D was less than naphthaleneacetic acid (NAA) and indole-3-acetie acid (IAA) at inducing the SE of Citrus (Citrus reticulata Banco.) [1] and Gladiolus (Gladiolus hort.) [41], and 2, 4-D is invalid and even hampers SE on Cherry [5] and Begonia gracilis [42]. Depending on the different stage of development of somatic embryos, 2,4-D would pro- mote inducing the production of embryo callus, but in- hibiting the embryoid differentiation stage. For instance, 2,4-D could induce synthesis of the embryonic proteins during SE of Lily, but it would inhibit the synthesis of protein for the development of an embryoid. Therefore, it would induce the somatic embryo of Lily scales when cultured in media containing 2,4-D around $15 \mathrm{~d}$ following transfer to the media without any PGR [11]. However, not all plants requires 2,4-D for SE. IAA is necessary to induce SE of Begonia cathayana Hemsl, but 2,4-D does not have any effect on it [42]. Picloram would induce the SE of banana rather than 2,4-D [43]. The somatic embryo of Gladiolus could be induced in media containing NAA but not in media containing other PGR [41].

The reasonable ratio of CTK and auxin is one of the major factors to induce horticultural plant SE. The high efficiency of SE in poinsettia depends on the ratio of CTK to auxin [31]. The high ratio of auxin to CTK would promote the SE of American chestnut [39], Bego- nia cathayana Hemsl [42] and Cyclamen [44], whereas a high ratio of CTK to auxin would promote apple SE. It is a requirement of two types of auxin and CTK to induce direct SE for Chrysanthemum morifolium [22], but walnut [45] and peach [4] require two types of CTK and IAA to induce SE.

Gibberellic acid (GA) and Abscisic acid (ABA) are not necessary for the induction of SE. GA has been shown to promote SE for Apple, Pear, Garnetberry, and Cherry and also plays an inhibition role in Citrus SE [2]. ABA has promoting or inhibitory effects depending on the specific plant. Wei et al. [43] had shown that ABA inhibited the SE of banana embryogenic suspension callus (ESC), and the extent of callus increased with increasing ABA concentration in the media. Different plants have specific requirements for $\mathrm{ABA}$ concentration. For example, increased concentrations of ABA $\left(100 \mathrm{mmol} \cdot \mathrm{L}^{-1}\right)$ was re- quired for high quality somatic embryos of cherry to induce formation [5]. However, the SE of Papaya would form in medium containing only ABA [38].

In a word, different PGR have diverse specialties, and a variety of explants have different requirements for these hormones. Considering the specificity of PGR re- quirement of explants, different types of PGR have to be applied in a reasonable ratio to promote the growth and development of SE.

\subsection{Nitrogen Source, Carbon Source, and Natural Addition}

The distinct types and amounts of nitrogen play a significant role in SE. In general, the MS which contains high amounts of $\mathrm{NH}_{4} \mathrm{NO}_{3}$ is always used in inducing SE. Different amino acids have distinct roles in plant SE. For example, Serine, Glntamine, Asn, and Ala promote SE. The effect of L-proline is the best one to promote petiole SE of apple among these 4 amino acids [6]. It has been shown that nitrogen-containing compounds could also promote SE instead of $\mathrm{NH}^{+4}$, but the effects of these compounds were less than that of $\mathrm{NH}^{+4}$.

Carbon as the energy source of explants balances osmotic pressure and plays an important role in plant SE. Li et al. [46] have shown that garlic SE could be adjusted by different concentrations of sucrose. In brief, the su- crose of $10-30 \mathrm{~g} \cdot \mathrm{Kg}^{-1}$ could promote garlic SE, but su- crose over $60 \mathrm{~g} \cdot \mathrm{Kg}^{-1}$ could inhibit the growth and deve- lopment of garlic SE. The distinct sources of carbon also impact embryogenesis. For instance, taking the cotyledon of melon "GT-1" as explants, indirect embryogenesis occurred when glucose was used as the carbon source, while direct embryogenesis was observed when the medium contained lactose [47]. Citrus SE efficiency increases 6 - 12 times by combining lactose with galactose insteading of sucrose alone [26]. Cucumber SE efficiency increases by combining mannitol with sucrose as the source of carbon [25]. However, sucrose induced cotyledon SE of Melon (Cucumis melo), but mannitol did not [48]. The effect of white sugar with $10-40 \mathrm{~g} \cdot \mathrm{L}^{-1}$ as the source of carbon is the best to induce the formation of somatic embryos among sucrose, glucose, and maltose when inducing Chinese chestnut SE; nevertheless, the mortality of American chestnut explants increases with increasing sugar concentration [39]. Longan (Dimocarpus longgana Lour) somatic embryos would form mature embryoids at high sugar concentration $\left(50 \mathrm{~g} \cdot \mathrm{L}^{-1}\right)$, but the transparent somatic embryos would lead to immature embryoids at low sugar concentration $\left(20 \mathrm{~g} \cdot \mathrm{L}^{-1}\right)$ [2].

The natural additions of hydrolyzed casein $(\mathrm{CH})$, malt wort (ME), and coconut wort (CW) as the cultural media provide more reduction of $\mathrm{N}$ than inorganic $\mathrm{N}$, which plays a specific role in inducing SE. However, natural additions play a variety of roles in specific species of plants because of the complex assortments of components in natural additions.

$\mathrm{CH}$ induces SE in many horticultural plants, such as grape, peach, sweet cherry, walnut [2], garlic [17], and celery [29]. In addition, $\mathrm{CH}$ promotes the formation of mature embryoids of leechee and high quality SE of poinsettia [49]. ME containing less $P$ plays a specific role in promoting citrus $\mathrm{SE}$ at the ME concentration of 500 $1000 \mathrm{mg} \cdot \mathrm{L}^{-1}$ without the addition of PGR in the medium 
[2]. Some scientists consider that ME is necessary for inducing SE of citrus. CW, which contains many components, has the obvious effect of promoting SE of many horticultural plants. For instance, the growth and development of the somatic embryoid of Papaya had been promoted with the addition of $2 \% \mathrm{CW}$ in the media [38]. The nucellus embryo SE efficiency of mango increased $18 \%$ and has a big volume of embryoids and very little abnormal embryoids with the addition of $20 \% \mathrm{CW}$ in the media. In addition, CW also promotes the growth and development of longan SE. On the contrary, CW inhibits SE of pear and apple [1].

\section{Application of SE in Horticulture Plants}

SE research has broad application prospects e.g., genetic engineering, germplasm preservation, seedling fast breeding, artificial seeds, hybrid zygotic embryo rescue, induced culture of somatic cell hybrids, haploid, triploid, and the individual choice of cell-induced mutations, and breeding, which have high importance in scientific research as well as great economic value in production. Briefly, three main aspects of applications of SE of horticultural plants will be discussed.

\subsection{Rapid Propagations of Horticultural Plants by SE}

The very high commercial value resulting from tissue culture techniques (i.e., rapid multiplication of superior cultivars and rootstock asexual reproduction) has already been demonstrated. In comparison to organogenesis, the advantage of SE is to generate the intact plant with the apical meristem and the primary root, avoiding a series of organogenesis problems: senescence, rejuvenation, rhizogenesis and difficult to transfer into soil. Therefore, SE has developed into an important research field in recent years. A typical example is to carry out embryonic callus suspension culture by using grape; there are a number of somatic embryos produced after $20 \mathrm{~d}$ by subculturing grape [1].

\subsection{The Transgenic Engineering of Horticultural Plants with Somatic Embryos as the Receptor}

With the rapid development of modern molecular biology techniques, molecular genetic breeding has become the important complemental method of traditional breeding to improve plant germplasms. In general, somatic embryos are originated from single cells, and the chimera frequency is very low; both of these advantages make it easy for the application towards breeding transgenic plants. Meanwhile, the simple operation, short cycle, and high transformation efficiency are advantages inducing embryo calluses as the receptors of transgenic plants. Currently, there are many successful plant transformations (e.g.,
Chrysanthemum [21], Rose (Rosa rugosa) [50], Eggplant (Solanum melongena Linn.), papaya [38], Walnut [51], Peach [52], Cherry [53], and Litchi (Litchi chinensis) [54]. In addition, genes have been expressed on the level of cell or calluses in some trees by transformation techniques. Comparing the successful transgenic engineering using somatic embryos as the recipients in foreign, our SE research is at the beginning of stage, we could expect that transgenic SE engineering would have a very broad application in future.

\subsection{Other Applications of SE in Horticultural Plants}

In addition to the application of rapid breeding and transgenic engineering, the application of SE of horticultural plants has also shown to be applicable towards breed improvement, like germplasm resource preservation, and protoplast culture. The plant somatic embryos provide a model experimental system studying plant cell development and differentiation, the expression of plant totipotency, crop improvement, and mutant screening. All of these is very important in both in theory and practical application. Endangered plant species could be preserved by the application of embryonic callus techniques under specific conditions. There are so many asexual cell lines produced during SE, which provide the material for screening mutants, cell fusing, protoplast regeneration, cell differentiation, and plant regeneration.

\section{The End}

Currently, there are problems which still need to be solved in the research of embryogenesis even though some research achievements have been employed in horticulture and forestry industries. For instances, both the tissue culture conditions and embryo transition efficiency should be further studied in order to improve the quality and quantity of embryogenesis; the inheritance stability and the molecular mechanism of embryogenesis should also be continued to study in detail. There are mainly two aspects on which we should focus in future. On the one hand, the model system of embryogenesis of horticultural plants, especially for fruit trees, should be built based on previous works in resent years. On the other hand, it is really important to carry out systemic research on the mechanisms of embryogenesis growth and developmental regulation, regeneration study of genetic variability. All of this research would promote researchers to further understand the embryogenesis mechanism, in essence, improving the application of embryogenesis research achievements in agricultural practices.

\section{REFERENCES}

[1] K. R. Cui and R. L. Dai, "Molecular Biology of Plant 
Somatic Embryogenesis,” Science Press, Beijing, 2000, pp. 48-54.

[2] Y. J. Chen and Z. X. Lai, "Researches and Utilization of Somatic Embryogenesis in Fruits and Trees," Journal of Fujian Agricultural University, Vol. 30, No. 3, 2001, pp. 420-426.

[3] X. L. Huang and Y. J. Li, "Morphogenesis and Regulation of Higher Plant Organ Culture in Vitro," Science Press, Beijing, 1995, pp. 46-72.

[4] G. H. Yan and Y. Zhou, "Plant Regeneration from Excised Immaturate Embryos of Peach (Prunus persica L.)," Acta Horticulturae Sinica, Vol. 29, No. 5, 2002, pp. 480482.

[5] G. March, E. Grenier, N. Miannay, G. Sulmont, H. David and A. David, "Potential of Somatic Embryogenesis in Prunus avium Immature Zygotic Embryos,” Plant Cell, Tissue and Organ Culture, Vol. 34, 1993, pp. 209-215. doi:10.1007/BF00036104

[6] K. D. Da, S. Zhang, Y. Z. Li and Z. J. Qi, "Direct Somatic Embryogenesis from in Vitro Leaves of Apple," Acta Horticulturae Sinica, Vol. 23, No. 3, 1996, pp. 241-245.

[7] C. L. Zhang, D. F. Chen, M. Kubalakova, J. Zhang, N. W. Scott, M. C. Elliott and A. Slater, "Efficient Somatic Embryogenesis in Sugar Beet (Beta vulgaris L.) Breeding Lines," Plant Cell, Tissue and Organ Culture, Vol. 93, 2008, pp. 209-221. doi:10.1007/s11240-008-9364-2

[8] Q. R. Sun, Q. Z. Liu and R. H. Zhao, "Somatic Embryo Genesis from in Vitro Leaves of Pear," Acta Horticulturae Sinica, Vol. 30, No. 1, 2003, pp. 85-86.

[9] A. K. A. Mandal and S. K. Datta, "Direct Somatic Embryogenesis and Plant Regeneration from Ray Florets of Chrysanthemum,” Biologia Plantarum, Vol. 49, No. 1, 2005, pp. 29-3311. doi:10.1007/s10535-005-0033-6

[10] X. M. Liu, P. H. Zhou, S. C. Qu, X. Y. Lu and Z. M. Luo, "In Vitro Induction of Indefinite Bubs and Somatic Embryos from Scale Leave of Tetraploid 'Longya Lily'," Acta Horticulturae Sinica, Vol. 24, No. 4, 1997, p. 353.

[11] A. Yantcheva, M. Vlahova and A. Antanassov, "Direct Somatic Embryogenesis and Plant Regeneration of Carnation (Dianthus caryophyllus L.)," Plant Cell Reports, Vol. 18, 1998, pp. 143-153. doi:10.1007/s002990050548

[12] X. M. Liu, P. H. Zhou, S. C. Qu, X. Y. Lu and Z. M. Luo, "In Vitro Induction of Indefinite Bubs and Somatic Embryos from Scale Leave of Tetraploid 'Longya Lily'," Acta Horticulturae Sinica, Vol. 24, No. 4, 1997, p. 353.

[13] G. H. Ma and N. Liu, "Direct Somatic Embryogenesis and Shoot Formation from Cultured Young Leaf of Kalanchoe blossfeldiana," Plant Physiology Communications, Vol. 39, No. 6, 2003, p. 625.

[14] W. P. Gow, J. T. Chen and W. C. Chang, "Effects of Genotype, Light Regime, Explant Position and Orientation on Direct Somatic Embryogenesis from Leaf Explants of Alaenopsis Orchid," Acta Physiologiae Plantarum, Vol. 31, No. 2, 2009, pp. 263-269. doi:10.1007/s11738-008-0243-6

[15] M. Rivera-Domínguez, M. A. Manzanilla-Ramírez, M.
Robles-González and M. A. Gómez-Lim, "Induction of Somatic Embryogenesis and Plant Regeneration of 'Ataulfo' Mango (Mangifera indica)," Plant Cell, Tissue and Organ Culture, Vol. 79, No. 1, 2004, pp. 101-104.

[16] A. Grapin, J. Schwendiman and C. Teisson, "Somatic Embryogenesis in Plantain Banana,” In Vitro Cellular \& Developmental Biology_Plant, Vol. 32, No. 2, 1996, pp. 66-71. doi:10.1007/BF02823133

[17] C. Robacher, "Somatic Embryogenesis and Plant Regeneration from Muscadine Grape Leaf Explant," Hort Science, Vol. 28, No. 1, 1993, pp. 53-55.

[18] L. Fereol, V. Chovelon and S. Causse, "Evidence of a Somatic Embryogenesis Process for Plant Regeneration in Garlic (Allium sativum L.),” Plant Cell Reports, Vol. 21, No. 3, 2002, pp. 197-203. doi:10.1007/s00299-002-0498-0

[19] K. M. S. Elmeer and M. J. Hennerty, "Observations on the Combined Effects of Light, NAA and 2,4-D on Somaticembryogenesis of Cucumber (Cucumis sativus) Hybrids," Plant Cell, Tissue and Organ Culture, Vol. 95, No. 3, 2008, pp. 381-384. doi:10.1007/s11240-008-9439-0

[20] L. P. Chen, B. L. Wang and M. F. Chen, "Studies on Somatic Embryogenesis of Euphorbia pulcherrima in Vitro Culture,” Plant Physiology Communications, Vol. 35, No. 6, 1999, pp. 463-465.

[21] J. J. Zamorano-Mendoza and J. M. Mejia-Munoz, "In Vitro Propagation of Gypsophila (Gypsophila paniculata L.) cv. Perfecta.-Revista-Chapingo,” Horticultural Services, Vol. 1, 1994, pp. 67-71.

[22] X. W. Jiang and Q. X. Zhang, "Studies on Transgenic Acceptor System of Ground-Cover Chrysanthemum via Indirect Somatic Embryogenesis," Forest Research, Vol. 20, No. 3, 2007, pp. 328-333.

[23] X. W. Jiang, F. J. Chen, M. Lu, M. Cai and Q. X. Zhang, "Direct Somatic Embryogenesis in Ground-Cover Chrysan-Themum," Journal of Beijing Forestry University, Vol. 30, No. 2, 2008, pp. 65-70.

[24] K. H. G. Ashok, H. N. Murthy and K. Y. Pack, (2003). "Embryogenesis and Plant Regeneration from Anther Culture of Cucumis sativus L.," Scientia Hoticulture, Vol. 98, No. 2, 2003, pp. 213-222. doi:10.1016/S0304-4238(03)00003-7

[25] H. R. Tang, Y. Q. Wang and Z. L. Ren, "An Overview of Progress on Somatic Embryogenesis and Transformation in Walnut," Scientia Silvae Sinicae, Vol. 36, No. 3, 2000, pp. 102-110.

[26] A. F. Yang, Y. M. Zhu and A. J. Hou, "Several Factors Affecting Somatic Embryos Derived from Cotyledons of Cucumber (Cucumis sativus)," Plant Physiology Communications, Vol. 39, No. 3, 2003, pp. 206-208.

[27] W. S. Chen and S. C. Su, "The Difference and Occurrence of Somatic Embryogenesis in Early Varieties of Walnut," Science \& Technology Information, Vol. 16, 2006, pp. 176-177.

[28] P. Wang, G. Wang and J. Ji, "Embryogenesis and Regeneration from Different of Vegetable Soybean," Soybean Science, Vol. 24, No. 4, 2005, pp. 314-316. 
[29] F. H. Bian, F. N. Qu, C. X. Zheng, C. R. You and X. Q. Gong, "Recent Advances in Cyclamen persicum Mill. Somatic Embryogenesis," Northern Horticulture, Vol. 8, 2007, pp. 70-72.

[30] H. Cui, Z. C. Guo and Y. L. Gui, "Studies on Somatic Embryogenesis and Desiccation Somatic embryos in Celery," Acta Botanica Sinica, Supplement A00, 1993, pp. 94-100.

[31] S. Werbrouck, T. Eeekhaut and P. Deber, "Induction and Conversion of Somatic Embryogenesis on the Anther Filament of spathiphyllum Schott.," Acta Hort, Vol. 520, 2000, pp. 263-269.

[32] G. F. Zhu, F. B. Lu, M. L. Chen and B. Q. Wang, (2004). "Somatic Embryogenesis and Plantlet Regeneration of Euphorbia pulcherrima," Subtropical Plant Science, Vol. 33, No. 4, 2004, pp. 37-38.

[33] S. S. Niu, S. W. Song, F. Yan and H. X. Miao, "Somatic Embryogenesis and Plantlet Regeneration in Citrullus lanatus cv. Zhengkang No. 4,” Journal of Fruit Science, Vol. 23, No. 3, 2006, pp. 406-410.

[34] Q. X. Zhang, Y. M. Fang, M. Lü and N. Chen, “A Preliminary Study on Induction of Adventitious Buds and Embryogenesis in Clematis Multi-Blue,” Acta Horticulturae Sinica, Vol. 34, No. 2, 2007, pp. 465-468.

[35] W. J. Xin, B. Xu, G. D. Wang, W. M. Guo, F. D. Wen and J. P. Jin, "Somatic Embryogenesis and Plant Regeneration of Anthurium andraeanum," Acta Horticulturae Sinica, Vol. 33, No. 6, 2006, pp. 1281-1286.

[36] S. L. Liu, B. W. Han and H. Z. Chen, "Somatic Embryogenesis and Cytological Observation from Petiole of Walnut (Juglans regia L.)," Journal of China Agricultural University, Vol. 18, 1992, pp. 29-32.

[37] L. Wang, X. M. Bao, B. Q. Huang and S. Hao, "Somatic Embryogenic Potential Determined by the Morphological Polarity of the Explant in Tissue Cultures of Freesia Refracta," Acta Botanica Sinica, Vol. 40, No. 2, 1998, pp. 138-143.

[38] S. G. Dewald and X. F. Wang, "Optimization of Mango Somatic Embryogenesis,” Tropical Crops Translation Series, Vol. 1, pp. 25-29.

[39] M. M. M. Fitch, "High Frequeacy Somatic Embryogenesis and Plant Regeneration from Papaya Hypocotyl Callus,” Plant Cell, Tissue and Organ Culture, Vol. 32, No. 2, 1993, pp. 205-212. doi:10.1007/BF00029844

[40] D. T. Carraway, H. D. Wilde and S. A. Merkle, "Somatic Embryogenesis and Gene Transfer in American Chestnut," Journal of American Chestnut Found, Vol. 8, 1994, pp. 29-33.

[41] T. Zhang, Z. Y. Cao and X. Y. Wang, "Induction of Somatic Embryogenesis and Plant Regeneration from Cotyledon and Hypocotyls Explants of Eruca Sativa Mill,” In Vitro Cellular Developmental Biology—Plant. Vol. 41, No. 5, 2005, pp. 655-657. doi:10.1079/IVP2005653

[42] B. Stefaniak, "Somatic Embryogenesis and Plant Regen- eration of Gladiolus (Gladiolus hort.),” Plant Cell Reports, Vol. 13, No. 7, 1994, pp. 386-389. doi:10.1007/BF00234143

[43] B. Castillo and M. A. L. Smith, "Direct Somatic Embryogenesis from Begonia gracilis Explants,” Plant Cell Reports, Vol. 16, No. 6, 1997, pp. 385-388.

[44] Y. R. Wei, H. Yang, B. Z. Huang, X. Huang, X. L. Huang, J. S. Qiu and L. B. Xu, "Effects of Picloram, ABA and TDZ on Somatic Embryogenesis of Banana," Acta Horticulturae Sinica, Vol. 34, No. 1, 2007, pp. 81- 86.

[45] T. Takejiro, M. Ikuo and M. Eisuke, "Somatic Embryogenesis of Cyclamen Persicum Mill. 'Anneke' from Aseptic Seedlings,” Plant Cell Reports, Vol. 15, No, 1-2, 1995, pp. 22-25.

[46] W. Tulecke and G. Mcgranahan, "Somatic Embryogenesis and Plant Regeneration from Cotyledons of Walnut,” Juglans regia L. Plant Science, Vol. 40, No. 1, 1985, pp. 57-63. doi:10.1016/0168-9452(85)90163-3

[47] X. Q. Li, S. F. Krasnyanski and S. S. Korban, “Optimization of the UidA Gene Transfer into Somatic Embryos of Rose via Agrobacterium Tumefaciens,” Plant Physiology and Biochemistry, Vol. 40, No. 5, 2002, pp. 453-459. doi:10.1016/S0981-9428(02)01394-3

[48] Y. T. Zeng, C. Z. Zhao and L. Lu, "Establishment of Plant Regeneration System through Somatic Embryogenesis of Cotyledons of Cucumis melo 'GT-1',' Journal of Gansu Agricultural University, Vol. 42, No. 2, 2007, pp. 39-42.

[49] H. Nakagawa and T. Saijyo, "Effect Sugar and ABA on Somatic Embryo Formation with Cotyledon Culture of Melon,” Foreign Crop Breeding, Vol. 21, No. 3, 2002, p. 75.

[50] Y. Xiao and G. Wang, "Studies on High Quality Somatic Embryogenesis Applied to Artificial Seed of Euphorbia Pulcherrima Willd,” Acta Horticulturae Sinica, Vol. 33, No. 1, 2006, pp. 175-178.

[51] B. X. Li and Z. H. Cheng, "Studies on the Induction Factors of Somatic Embryogenesis in Garlic (Allium sativum L.)," Journal of Northwest Sci-Tech University of Agriculture and Forestry, Vol. 30, No. 5, 2002, pp. 31-34.

[52] H. R. Tang, M. Wallbraun, Z. L. Ren, G. M. Reustle and G. Krczal, "Genetic Transformation of the Trichoderma Endochitinase Gene ThEn 42 to Somatic Embryos of English Walnut,” Acta Horticulturae Sinica, Vol. 28, No. 1, 2001, pp. 12-18.

[53] R. Scorza, P. H. Morgens, J. M. Cordts, S. Mante and A. M. Callahan, "Agrobacterium-Mediated Transformation of Peach (Prunus persica L. Batch) Leaf Segments, Immature Embryos and Long Term Embryogenic Callus,” In Vitro Cellular \& Developmental Biology, Vol. 26, 1990, pp. 829-834. doi:10.1007/BF02623625

[54] G. Q. Song and K. C. Sink, "Transformation of Montmorency Sour Cherry (Prunus cerasus L.) and Gisela 6 ( $P$. cerasus $\times P$. canescens) Cherry Rootstock Mediated by Agrobacterium Tumefaciens,” Plant Cell Report, Vol. 25, No. 2, 2006, pp. 117-123. doi:10.1007/s00299-005-0038-9 